\title{
Pneumomediastinum after Endoscopic Transmural Drainage of an Acute Pseudocyst: Not All That Scary!
}

\author{
Surinder Singh Rana ${ }^{1}$ Mandeep Kang ${ }^{2}$ Nikhil Bush ${ }^{1}$ Rajesh Gupta ${ }^{3}$
}

${ }^{1}$ Department of Gastroenterology, Postgraduate Institute of Medical Education and Research (PGIMER), Chandigarh, India

2 Department of Radiology, Postgraduate Institute of Medical Education and Research (PGIMER), Chandigarh, India

${ }^{3}$ Department of Surgical Gastroenterology, Postgraduate Institute of Medical Education and Research (PGIMER), Chandigarh, India

J Digest Endosc 2021;12:253-254.

A 29-year-old man presented with shortness of breath associated with abdominal pain and distension of 2 weeks' duration. He was diagnosed with alcohol-related acute necrotizing pancreatitis 4 months ago, and computed tomography (CT) done at 3 months of illness revealed a $2.5-\mathrm{cm}$ collection in the neck of the pancreas with dilated upstream main pancreatic duct, suggesting a diagnosis of disconnected pancreatic duct. The investigations done during the current admission revealed hypoxia with amylase-rich exudative ascites (- Fig. 1A) and a large acute pseudocyst (AP) (-Fig. 1B). He underwent endoscopic ultrasound-guided transmural drainage of AP with a fully covered, self-expandable biflanged metal stent (BFMS) (-Fig. 1C). Post drainage,
Address for correspondence Surinder Singh Rana, MD, DM, FASGE, AGAF, Department of Gastroenterology, Postgraduate Institute of Medical Education and Research (PGIMER), Chandigarh -160012, India (e-mail: drsurinderrana@gmail.com).

the patient had marked improvement in symptoms but developed palpable subcutaneous emphysema in the neck. CT chest revealed pneumomediastinum (-Fig. 2A; arrows) and $\mathrm{CT}$ abdomen revealed marked reduction in the size of AP, resolution of ascites, and pneumoperitoneum (-Fig. 2B; arrows) along with pneumoretroperitoneum. The patient was treated with intravenous antibiotics, oxygen supplementation, and nasojejunal enteral feeding. The subcutaneous emphysema, tachypnea, and acute lung injury resolved in the following 72 hours. Oral feeding was started 7 days later and the BFMS was replaced with two 7-Fr double pigtail stents 12 days post drainage. Thereafter, the patient was discharged and is currently asymptomatic.

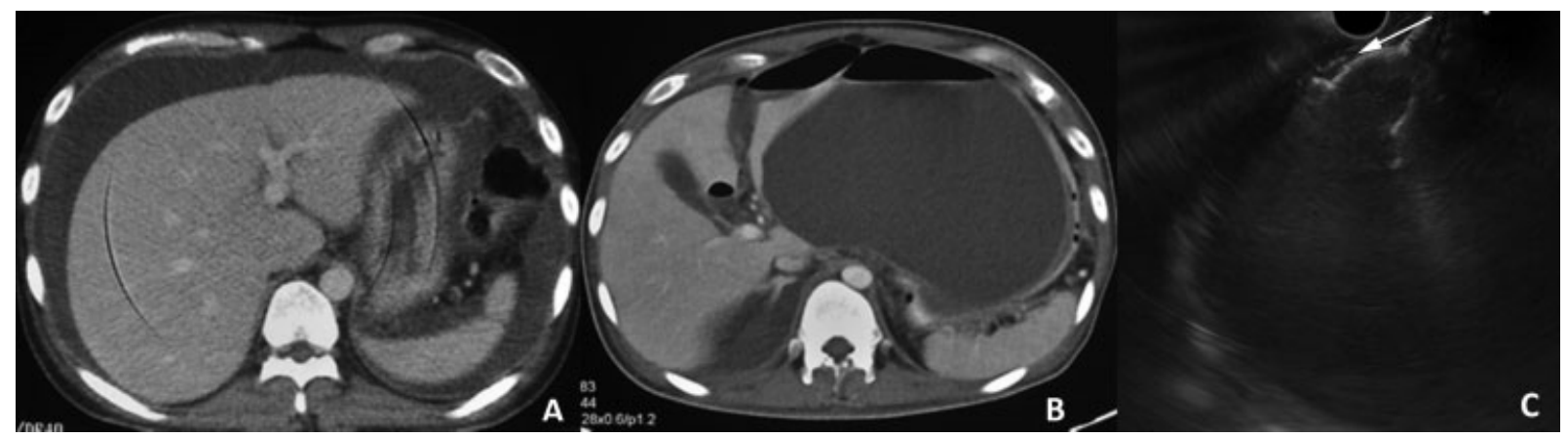

Fig. 1 (A) Contrast-enhanced CT (CECT) of the abdomen: pancreatic ascites. (B) CECT abdomen: large pseudocyst. (C) EUS-guided transmural drainage of the pseudocyst using biflanged metal stent (BFMS) (arrow).

DOI https://doi.org/ 10.1055/s-0041-1741065. ISSN 0976-5042. (c) 2022. Society of Gastrointestinal Endoscopy of India. All rights reserved.

This is an open access article published by Thieme under the terms of the Creative Commons Attribution-NonDerivative-NonCommercial-License, permitting copying and reproduction so long as the original work is given appropriate credit. Contents may not be used for commercial purposes, or adapted, remixed, transformed or built upon. (https://creativecommons.org/ licenses/by-nc-nd/4.0/)

Thieme Medical and Scientific Publishers Pvt. Ltd., A-12, 2nd Floor, Sector 2, Noida-201301 UP, India 


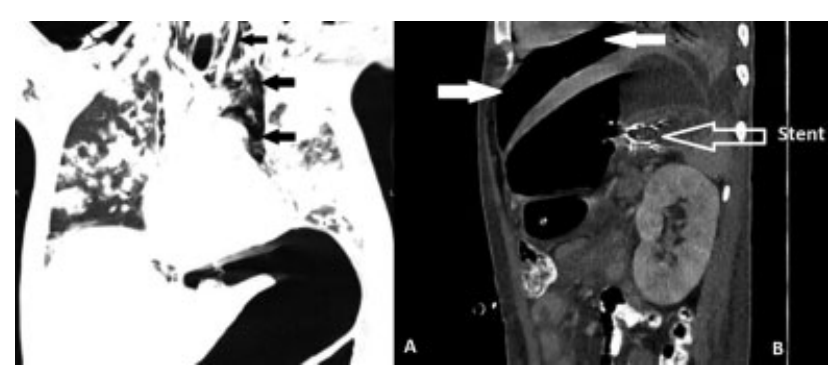

Fig. 2 (A) CT chest: pneumomediastinum (arrows). (B) CT abdomen: marked reduction in the size of AP, resolution of ascites, and pneumoperitoneum (arrows).

Leaking pancreatic pseudocyst into the peritoneum leads to development of pancreatic ascites, and transmural drainage of this peritoneum communicating pseudocyst can provide peritoneal access to the intraluminal air, leading to pneumoperitoneum. ${ }^{1}$ Use of BFMS for transmural drainage can lead to egress of large amount of intraluminal air, leading to significant amount of pneumoperitoneum. Lack of completely enclosing wall of the pseudocyst can also provide retroperitoneal access to the intraluminal air, leading to pneumoretroperitoneum. Also, as the retroperitoneum and the mediastinum communicate with each other through the esophageal and aortic hiatus, the air can track into the mediastinum. ${ }^{2}$

\section{Author Contributions}

S. S. R. collected and interpreted data for this study and also drafted the manuscript. M. K., N. B., and R. G. collected and interpreted data for this study.

\section{Funding}

None.

\section{Conflict of Interest}

None declared.

\section{References}

1 Rana SS, Sharma RK, Gupta R. Endoscopic management of pancreatic ascites due to duct disruption following acute necrotizing pancreatitis. JGH Open 2018;3(02):111-116

2 Bhasin DK, Rana SS, Rao C, et al. Clinical presentation, radiological features, and endoscopic management of mediastinal pseudocysts: experience of a decade. Gastrointest Endosc 2012;76(05): 1056-1060 